\title{
Evaluation of the content validity index of the Australian/Canadian osteoarthritis hand index, the patient-rated wrist/hand evaluation and the thumb disability exam in people with hand arthritis
}

\author{
Pavlos Bobos ${ }^{1,2,3,4^{*}}$ (D), Joy C. MacDermid ${ }^{1,2,3,5}$, Eleni C. Boutsikari ${ }^{6}$, Emily A. Lalone ${ }^{7}$, Louis Ferreira ${ }^{7}$ and
} Ruby Grewal ${ }^{3}$

\begin{abstract}
Background: The Australian/Canadian Osteoarthritis Hand Index (AUSCAN), the Patient-Rated Wrist/Hand Evaluation (PRWHE) and the Thumb Disability Exam (TDX) are patient-reported outcome measures (PROM) designed to assess pain and hand function in patients with hand arthritis, hand pain and disability, or thumb pathology respectively. This study evaluated the content validity of AUSCAN, PRWHE and TDX in people with hand arthritis.

Methods: This study enrolled participants with hand arthritis to rate the items of all 3 PROM in terms of relevance and clarity. The Content Validity Index (CVI) was computed for each item in each scale (I-CVI) as well as for the overall scale (S-CVI). Kappa was used to determine the inter-rater agreement among the raters.

Results: Overall, 64 individuals with hand arthritis (27\% with OA, 67\% with rheumatoid arthritis and 6\% with psoriatic arthritis) participated in the study. The I-CVI for all items and all scales were very high $(\mathrm{I}-\mathrm{CVI}>0.76)$ and the modified Kappa agreement among the raters demonstrated excellent agreement $(k>0.76)$. The S-CVI for all PROMs was very high for relevance (AUSCAN $=0.92,95 \% \mathrm{Cl} 0.90$ to $0.94 ; \mathrm{PRWHE}=0.85,95 \% \mathrm{Cl} 0.82$ to 0.88 and TDX $=0.87$, $95 \% \mathrm{Cl} 0.85$ to 0.89 ) and for clarity (AUSCAN $=0.99,95 \% \mathrm{Cl} 0.98$ to $1.00 ; \mathrm{PRWHE}=0.95,95 \% \mathrm{Cl} 0.93$ to 0.97 and TDX $=0.91,95 \% \mathrm{Cl} 0.89$ to 0.94 ), respectively.
\end{abstract}

Conclusions: This study demonstrated very high content validity indices for the AUSCAN, PRWHE and TDX; with strong consensus across raters. This augments prior studies demonstrating appropriate statistical measurement properties, to provide confidence that all three measures assess important patient concepts of pain and disability.

Keywords: Osteoarthritis, Rheumatoid arthritis, Psoriatic arthritis, Content validity, Hand arthritis

\footnotetext{
* Correspondence: pbobos@uwo.ca

'School of Physical Therapy, Department of Health and Rehabilitation Sciences, Western University, London, ON, Canada

${ }^{2}$ Western's Bone and Joint Institute, Collaborative Program of Musculoskeletal Health Research, Western University, London, ON, Canada

Full list of author information is available at the end of the article
}

(c) The Author(s). 2020 Open Access This article is licensed under a Creative Commons Attribution 4.0 International License, which permits use, sharing, adaptation, distribution and reproduction in any medium or format, as long as you give appropriate credit to the original author(s) and the source, provide a link to the Creative Commons licence, and indicate if changes were made. The images or other third party material in this article are included in the article's Creative Commons licence, unless indicated otherwise in a credit line to the material. If material is not included in the article's Creative Commons licence and your intended use is not permitted by statutory regulation or exceeds the permitted use, you will need to obtain permission directly from the copyright holder. To view a copy of this licence, visit http://creativecommons.org/licenses/by/4.0/. The Creative Commons Public Domain Dedication waiver (http://creativecommons.org/publicdomain/zero/1.0/) applies to the data made available in this article, unless otherwise stated in a credit line to the data. 


\section{Introduction}

Hand osteoarthritis (OA) is one of the most common musculoskeletal diseases and a leading cause of disability with an increasing prevalence mainly attributed to increased life expectancy $[1,2]$. Clinical characteristics of hand OA typically involve pain, reduced hand function, decreased hand grip strength, poor quality of life $[3,4]$ joint degeneration, bony enlargements and joint swelling [5]. Rheumatoid arthritis, although leading to bone tissue abnormalities, loss of joint function and impact on quality of life similarly to OA, is a distinct pathology that mainly targets synovial and soft tissue structures [6].

Patient-reported outcome measures (PROMs) are often administered to assess any health-related changes that may have occurred as a consequence of healthmanagement interventions $[7,8]$. Many properties are important [9-13] during an instrument development such as reliability and validity but a key property is considered to be content validity [14]. Content validity can be defined as the degree of which the instrument or the questionnaire is an adequate reflection of the construct being measured [15]. Based on the Consensus-based Standards of the selection of health Measurement Instruments (COSMIN) initiative content validity is considered as one of the most important measurement properties [14]. While reliability, responsiveness and other types of validity can be pivotal for an outcome assessment they may be insufficient to establish the validity of a PROM [16]. When PROMs include irrelevant items and lack of clarity they are inefficient, and may have weaker measurement properties [14]. Most importantly, if key aspects are missing or the questions are not relevant responses, they may not reflect patient status or concerns, and may be biased because patients may get frustrated [17].

The Australian/Canadian Osteoarthritis Hand Index (AUSCAN) [18], the Patient-Rated Wrist/Hand Evaluation (PRWHE) [18] and the Thumb Disability Exam (TDX) [19] are clinical tools designed to assess pain and hand function in hand arthritis [18-21]. Both AUSCAN and PRWHE have demonstrated construct validity with verbal rating scale, had high internal consistency, and correlated with each other at baseline and follow-up time points in patients with early thumb carpometacarpal OA [18]. However, previous studies have reported inconsistent results about construct validity of AUSCAN [22-24]. Haugen et al. showed that AUSCAN total index lacks construct validity with items contributing to separate scales of pain, stiffness, and physical functioning [24]. Also, a recent update of PRWHE was performed to improve the clarity and applicability of items, but this version has not been compared to the AUSCAN and it is important to assess the content validity of the revised scale. The TDX is a more recently developed scale that has not been compared to either the PRWHE or
AUSCAN. Although, previous studies have demonstrated appropriate statistical measurement properties, content validity evaluations are needed to ensure that the constructs being evaluated are those intended, and that items are interpreted probably by potential respondents. Limited investigation of content validity has been reported for any of these three questionnaires. Therefore, we aimed to investigate the quantification of content validity index by asking patients with hand arthritis to rate each of the instruments items in terms of relevance and clarity.

\section{Primary objective}

To evaluate the Content Validity Index (CVI) of the Australian/Canadian Osteoarthritis Hand Index (AUSC AN), the Patient-Rated Wrist/Hand Evaluation (PRWH E), and the Thumb Disability Exam (TDX) in patients with hand arthritis.

\section{Methods \\ Study design}

This study was a cross-sectional design that investigated the content validity of patient-reported outcomes (AUSCAN, PRWHE and TDX) for hand arthritis. Ethical approval was granted from the Hamilton Integrated Research Ethics Board (HiREB).

\section{Inclusion criteria}

1. The participant was able and willing to provide informed consent

2. Participants were between $18-85$ years old

3. The participant had hand arthritis.

4. The participant can read and write English.

\section{Exclusion criteria}

1. Hand pathologies or conditions other than arthritis

2. Inability to answer the survey questions in English.

\section{Setting and recruitment}

Participants were recruited through poster advertisements at The Roth McFarlane Hand and Upper Limb Centre (HULC) at St. Joseph's Health Care Hospital in London, Ontario and through The Arthritis Society main website. The patients that expressed interest to participate in the study received a letter of information about the survey. Both electronic and paper versions of the survey were available for participants. An email with the link of the online survey was sent out to the participants that were interested to complete the electronic version. The electronic version was hosted on Qualtrics from May 2019 till February 2020 which is a secure data collection platform [25]. Participants were asked to provide consent to proceed into the survey questions. Allthe 
items were rated for relevance and clarity in an order (AUSCAN, PRWHE, TDX). Participants were asked to rate the relevance and clarity of each item of AUSCAN, PRWHE and TDX.

\section{Patient-reported outcome measures}

The Australian/Canadian Osteoarthritis Hand Index (AUSCAN) is a 15-item self-reported disease specific questionnaire measuring pain (5-items), function (9items) and stiffness (1-item) in the hand on a scale from 0 - none to 4 - extreme for all items $[18,20]$. The Patient-Rated Wrist/Hand Evaluation (PRWHE) is a self-administered questionnaire which has 2 subscales of pain (5-items) and function (10-items). The PRWHE was originally developed and tested for people with distal radius fracture (DRF) [21, 26, 27] and later validated as applicable to the wrist/hand for multiple conditions including arthritis as the PRWHE [18, 28]. Each item is scored from 0 to 10 scale which 10 indicates the worst possible pain or disability. The Thumb Disability Exam (TDX) is composed of 20 questions divided into $3 \mathrm{sec}-$ tions: hand function (11-items), pain (5-items) and satisfaction (4-items). Each item for hand function is scored from 1 - not difficult to 5 - unable, for level of pain 1 never to 5 - always and for satisfaction from 1 - very satisfied to 5 - very dissatisfied [19].

\section{Data analysis}

Descriptive statistics were used to capture the demographics characteristics (age, diagnosis, medications and whether they had surgery or not) of the included sample. A Content Validity Index (CVI) value was computed for each item on the AUSCAN, PRWHE and TDX (I-CVI) as well as for the overall scale (S-CVI). To calculate an item-level CVI (I-CVI), patients with hand arthritis were asked to rate the relevance of each item, on a 4-point scale. Four ordinal points were used foreach scale which was $1=$ not relevant, $2=$ somewhat relevant, $3=$ quite relevant, $4=$ highly relevant. Then, for each item, the ICVI was computed as the number of patients giving a rating of either 3 or 4 , divided by the number of ratersthat is, the proportion in agreement about relevance and clarity which is between 0 and 1.The S-CVI was calculated by averaging across the I-CVIs of each PROM. To calculate the modified kappa statistic, the probability of chance agreement $(\mathrm{Pc})$ was first calculated for each item by the following formula: $\mathrm{Pc}=\left[\mathrm{N} ! / \mathrm{A} !(\mathrm{N}-\mathrm{A}) !{ }^{*} 0.5^{\mathrm{N}}\right.$ with $\mathrm{N}$ being the number of raters (patients with arthritis) and $\mathrm{A}$ is the number of patients that agree that the item was clear or relevant [29]. Then Kappa was calculated of entering the probability of chance agreement (Pc) and content validity index of each item (I-CVI) in the following formula: $\mathrm{K}=(\mathrm{I}-\mathrm{CVI}-\mathrm{PC}) /(1-\mathrm{PC})$ [29]. Kappa values of 0.74 and above were considered as excellent, 0.60 to 0.74 as good and 0.54 to 0.59 as fair [30]. We performed a Shapiro-Wilk as the omnibus test for assessing univariate normality of each S-CVI distribution, in both relevance and clarity subscales of PROMs. Then, the S-CVI scores were compared with a paired student's t-Test if normality assumption was met or with Wilcoxon paired signed-ranks test, if assumptions of normality were violated [31]. We conducted all the analyses with STATA (StataCorp. 2019. Stata Statistical Software: Release 16. College Station, TX: StataCorp LLC).

\section{Results}

Overall, 64 individuals with hand arthritis $(27 \%$ with hand OA, 67\% with rheumatoid arthritis in the hand and $6 \%$ with psoriatic arthritis) participated in the study. Four individuals were excluded from the analysis because their arthritis was not affecting their hand. The majority of the participants (66\%) were taking pain medication on a daily basis (Table 1). All individuals completed the electronic version of the survey.

\section{Content validity index and modified kappa agreement of the AUSCAN}

The I-CVI and the S-CVI supported the content validity of the hand pain, stiffness and function items and subscales of the AUSCANs (Table 2). Five items of pain subscale were rated for relevancy and clarity with I-CVI scores ranging from 0.86 to 0.96 and from 0.92 to 1.00

Table 1 Demographics of study participants

\begin{tabular}{lll}
\hline Variable & $\mathbf{n}$ & Percentage \% \\
\hline Age, years & 1 & $12 \%$ \\
$18-24$ & 8 & $13 \%$ \\
$25-34$ & 13 & $20 \%$ \\
$35-44$ & 17 & $27 \%$ \\
$45-54$ & 19 & $27 \%$ \\
$55-64$ & 5 & $78 \%$ \\
$65-74$ & 1 & $2 \%$ \\
$75-84$ & & \\
Diagnosis & 17 & $27 \%$ \\
Osteoarthritis & 43 & $67 \%$ \\
Rheumatoid arthritis & 4 & $6 \%$ \\
Psoriatic arthritis & & \\
Frequency of medication & 42 & $66 \%$ \\
Daily & 10 & $16 \%$ \\
Upon pain & 12 & $19 \%$ \\
Other & & $77 \%$ \\
Surgery & 15 & $23 \%$ \\
No & 49 & \\
Yes & & \\
\hline
\end{tabular}


Table 2 Content validity index of item relevancy and clarity, and Modified Kappa agreement of the Australian and Canadian Osteoarthritis Index (AUSCAN)

\begin{tabular}{|c|c|c|c|c|c|c|c|c|c|}
\hline \multirow[t]{2}{*}{ Item } & \multicolumn{4}{|l|}{ Relevance } & \multicolumn{4}{|l|}{ Clarity } & \multirow[t]{2}{*}{ Interpretation } \\
\hline & Agreement & $\mathrm{I}-\mathrm{CVI}^{*}$ & $\mathrm{Pc}^{* *}$ & $\mathrm{~K}^{* * *}$ & Agreement & $\mathrm{I}-\mathrm{CVI}^{*}$ & $\mathrm{Pc}^{* *}$ & $\mathrm{~K}^{* * *}$ & \\
\hline \multicolumn{10}{|l|}{ Rate your pain } \\
\hline At rest & $49 / 57$ & 0.86 & $<10^{-5}$ & 0.86 & $49 / 50$ & 0.98 & $<10^{-5}$ & 0.98 & Excellent \\
\hline Gripping & $55 / 57$ & 0.96 & $<10^{-5}$ & 0.96 & $49 / 49$ & 1.00 & $<10^{-5}$ & 1.00 & Excellent \\
\hline Lifting & $55 / 57$ & 0.96 & $<10^{-5}$ & 0.96 & $49 / 50$ & 0.98 & $<10^{-5}$ & 0.98 & Excellent \\
\hline Turning & $54 / 57$ & 0.95 & $<10^{-5}$ & 0.95 & $46 / 50$ & 0.92 & $<10^{-5}$ & 0.92 & Excellent \\
\hline Squeezing & $55 / 57$ & 0.96 & $<10^{-5}$ & 0.96 & $50 / 50$ & 1.00 & $<10^{-5}$ & 1.00 & Excellent \\
\hline \multicolumn{10}{|l|}{ Rate your stiffness } \\
\hline After first wakening in the morning & $52 / 56$ & 0.93 & $<10^{-5}$ & 0.93 & $48 / 48$ & 1.00 & $<10^{-5}$ & 1.00 & Excellent \\
\hline \multicolumn{10}{|l|}{ Rate your difficulty when } \\
\hline Turning taps/faucets on & $51 / 58$ & 0.88 & $<10^{-5}$ & 0.88 & $51 / 51$ & 1.00 & $<10^{-5}$ & 1.00 & Excellent \\
\hline Turning a round doorknob or handle & $54 / 59$ & 0.92 & $<10^{-5}$ & 0.92 & $53 / 53$ & 1.00 & $<10^{-5}$ & 1.00 & Excellent \\
\hline Doing up buttons & $52 / 59$ & 0.88 & $<10^{-5}$ & 0.88 & $52 / 52$ & 1.00 & $<10^{-5}$ & 1.00 & Excellent \\
\hline Fastening jewellery & $52 / 59$ & 0.88 & $<10^{-5}$ & 0.88 & $53 / 53$ & 1.00 & $<10^{-5}$ & 1.00 & Excellent \\
\hline Opening a new jar & $57 / 59$ & 0.97 & $<10^{-5}$ & 0.97 & $53 / 53$ & 1.00 & $<10^{-5}$ & 1.00 & Excellent \\
\hline Carrying a full pot with one hand & $56 / 59$ & 0.95 & $<10^{-5}$ & 0.95 & $52 / 53$ & 0.98 & $<10^{-5}$ & 0.98 & Excellent \\
\hline Peeling vegetables/fruits & $56 / 59$ & 0.95 & $<10^{-5}$ & 0.95 & $53 / 53$ & 1.00 & $<10^{-5}$ & 1.00 & Excellent \\
\hline Picking up large heavy objects & $55 / 59$ & 0.93 & $<10^{-5}$ & 0.93 & $51 / 51$ & 1.00 & $<10^{-5}$ & 1.00 & Excellent \\
\hline Wringing out wash cloths & $52 / 59$ & 0.88 & $<10^{-5}$ & 0.88 & $50 / 51$ & 0.98 & $<10^{-5}$ & 0.98 & Excellent \\
\hline S - CVI & \multicolumn{4}{|c|}{$\mathbf{0 . 9 2}(95 \%$ Cl: 0.90 to 0.94$)$} & \multicolumn{5}{|c|}{$\mathbf{0 . 9 9}$ (95\% Cl: 0.98 to 1.00$)$} \\
\hline
\end{tabular}

NOTE: *I-CVI: item-level content validity index, ${ }^{* *}$ pc (probability of a chance occurrence) was computed using the formula: $\mathrm{pc}=[\mathrm{N}$ ! /A! (N $-\mathrm{A})$ !] ${ }^{*} \cdot 5^{\mathbf{N}}$ where $\mathrm{N}=$ number of raters and $\mathrm{A}=$ number of raters who agree that the item is relevant or clear, ${ }^{* * *} \mathrm{~K}$ (Modified Kappa) was computed using the formula: $\mathrm{K}=(\mathrm{I}-\mathrm{CVI}-\mathrm{PC}) /(1-$ $\mathrm{PC}$ ). Interpretation criteria for Kappa, using guidelines described in Cicchetti and Sparrow (1981): Fair $=\mathrm{K}$ of 0.40 to 0.59 ; Good $=\mathrm{K}$ of 0.60 to 0.74 ; and Excellent $=$ $\mathrm{K}>0.74$. I-CVI, item-level content validity index; scale-level content validity index, average (S-CVI/Ave)

respectively. For 1 -item in stiffness subscale the I-CVI was found 0.93 for relevancy and 1.00 for clarity. For function subscale, 9-items were rated for relevancy and clarity with an I-CVI ranging from 0.88 to 0.97 and from 0.98 to 1.00 respectively. The S-CVI for AUSCAN was found 0.92 , 95\% CI: 0.90 to 0.94 for relevance and 0.99, 95\% CI: 0.98 to 1.00 for clarity. The modified Kappa agreement for every item of the AUSCAN demonstrated excellent agreement ( $\mathrm{K}$ ranging from 0.86 to 1.00 ).

\section{Content validity index and modified kappa agreement of the PRWHE}

The I-CVI and the S-CVI of the PRWHE for pain subscale and function subscales all supported the content validity of the PRWHE (Table 3). Five items of pain subscale were rated for relevancy and clarity with I-CVI values ranging from 0.79 to 0.89 and from 0.87 to 0.94 , respectively. For function subscales, 10 items were rated for relevancy and clarity with ICVI values ranging from 0.79 to 0.95 and from 0.92 to 1.00 respectively. The S-CVI for PRWHE was 0.85 , $95 \%$ confidence intervals $(\mathrm{CI}): 0.82$ to 0.88 for relevance and 0.95 , 95\%CI: 0.93 to 0.97 for clarity. The modified Kappa agreement for every item of PRWHE demonstrated excellent agreement (K ranging from 0.79 to 1.00 ).

\section{Content validity index and modified kappa agreement of the TDX}

The I-CVI and the S-CVI supported the content validity of the TDX for hand function, pain and satisfaction subscales (Table 4). Eleven items of hand function were rated as relevant and clear with I-CVI values ranging from 0.82 to 0.93 and from 0.94 to 0.98 respectively. For pain subscale, five items were rated as relevant and clarity with ICVI scores ranging from 0.78 to 0.85 and from 0.77 to 0.86 respectively. For the satisfaction subscale, four items were rated as relevant and clear based on I-CVI demonstrating scores from 0.83 to 0.95 and from 0.88 to 0.91 . The S-CVI of TDX was rated as relevant and clear based on scores of $0.87,95 \%$ CI: 0.85 to 0.89 for relevancy and 0.91, 95\% CI: 0.89 to 0.94 for clarity. The modified Kappa agreement demonstrated excellent inter-rater agreement on item ratings (K ranging from 0.77 to 0.98 ).

\section{Discussion}

This study established a high level of content validity for AUSCAN, PRWHE and TDX for patients with hand arthritis. The content validity index was very high for all the individual items for each questionnaire (I-CVI > 0.77 ) and for the overall score (S-CVI $>0.85)$ in terms of 
Table 3 Content validity index of item relevancy and clarity and Modified Kappa agreement of Patient Rated Wrist/Hand Evaluation (PRWHE)

\begin{tabular}{|c|c|c|c|c|c|c|c|c|c|}
\hline \multirow[t]{2}{*}{ Item } & \multicolumn{4}{|l|}{ Relevance } & \multicolumn{4}{|l|}{ Clarity } & \multirow[t]{2}{*}{ Interpretation } \\
\hline & Agreement & $\mathrm{I}^{\mathrm{I}} \mathrm{CVI}$ & $\mathrm{Pc}^{* *}$ & $\mathrm{~K}^{* * *}$ & Agreement & $\begin{array}{l}\mathrm{I}- \\
\mathrm{CVI}\end{array}$ & $\mathrm{Pc}^{* *}$ & $\mathrm{~K}^{* * *}$ & \\
\hline \multicolumn{10}{|l|}{ 1. Pain subscale } \\
\hline Rate your pain: At rest & $51 / 64$ & 0.80 & $\begin{array}{l}<10 \\
-5\end{array}$ & 0.80 & $50 / 53$ & 0.94 & $\begin{array}{l}<-5 \\
-10\end{array}$ & 0.94 & Excellent \\
\hline $\begin{array}{l}\text { Rate your pain: When doing a task with a repeated wrist } \\
\text { movement }\end{array}$ & $54 / 64$ & 0.83 & $<{ }_{-5}^{<} 10$ & 0.83 & $49 / 53$ & 0.92 & $<{ }_{-5} 10$ & 0.92 & Excellent \\
\hline Rate your pain: When lifting a heavy object & $54 / 64$ & 0.83 & $\begin{array}{l}< \\
-5\end{array}$ & 0.83 & $50 / 53$ & 0.94 & $\begin{array}{l}<-5 \\
-50\end{array}$ & 0.94 & Excellent \\
\hline Rate your pain: When it is at its worst & $57 / 64$ & 0.89 & ${ }_{-5}^{<} 10$ & 0.89 & $49 / 53$ & 0.92 & $\underset{-5}{<} 10$ & 0.92 & Excellent \\
\hline How often do you have pain? & $50 / 63$ & 0.79 & $\underset{-5}{<} 10$ & 0.79 & $47 / 54$ & 0.87 & $\underset{-5}{<} 10$ & 0.87 & Excellent \\
\hline
\end{tabular}

\section{Function}

\section{A. Specific activities}

Cut meat using a knife in my affected hand

$0.8452 / 52$

$1.00 \underset{-5}{<} 10 \quad 1.00$ Excellent

$1.00<10 \quad 1.00$ Excellent

Fasten buttons on my shirt

Use my affected hand to push up from a chair

Carry a $10 \mathrm{lb}$. object in my affected hand

\section{B. Usual activities}

Personal care activities (dressing, washing)

Household work (cleaning, maintenance)

Work (your job or usual everyday work)

Recreational activities

$\begin{array}{lllll}53 / 61 & 0.87 & \leq 10 & 0.87 & 50 / 53 \\ & & & & \\ 57 / 60 & 0.95 & \leq 10 & 0.95 & 49 / 53 \\ & & & & \\ 52 / 60 & 0.87 & \leq 10 & 0.87 & 49 / 53 \\ & & & & \\ 54 / 60 & 0.90 & \leq 10 & 0.90 & 51 / 53\end{array}$

\begin{tabular}{|c|c|c|c|}
\hline 0.94 & $\begin{array}{l}< \\
-5\end{array}$ & 0.94 & Excellent \\
\hline 0.92 & $\underset{-5}{<} 10$ & 0.92 & Excellent \\
\hline 0.92 & $\begin{array}{l}< \\
-5\end{array}$ & 0.92 & Excellent \\
\hline 0.96 & $<10$ & 0.96 & Excellent \\
\hline
\end{tabular}

0.95 (95\% Cl: 0.93 to 0.97 )

\section{S - CVI/Ave}

NOTE: *I-CVI: item-level content validity index, ${ }^{* *} \mathrm{pc}$ (probability of a chance occurrence) was computed using the formula: $\mathrm{pc}=\left[\mathrm{N} ! / \mathrm{A} !(\mathrm{N}-\mathrm{A})\right.$ ! ${ }^{*} \cdot 5^{\mathbf{N}}$ where $\mathrm{N}=$ number of raters and $\mathrm{A}=$ number of raters who agree that the item is relevant or clear, ${ }^{* *} \mathrm{~K}$ (Modified Kappa) was computed using the formula: $\mathrm{K}=(\mathrm{I}-\mathrm{CVI}-\mathrm{PC}) /(1-$ $\mathrm{PC}$ ). Interpretation criteria for Kappa, using guidelines described in Cicchetti and Sparrow (1981): Fair $=\mathrm{K}$ of 0.40 to 0.59 ; Good $=\mathrm{K}$ of 0.60 to 0.74 ; and Excellent $=$ $\mathrm{K}>0.74$. I-CVI, item-level content validity index; scale-level content validity index, average (S-CVI/Ave)

relevancy and clarity, exceeding the recommended benchmarks of 0.78 respectively [29]. The Kappa interrater agreement of $>0.75$ was excellent across all the individual items for all PROMs (AUSCAN, PRWHE and TDX) among the raters [29]. Together these data provide confidence in our assessment since multiple raters agreed on the high content validity scores obtained.

For the AUSCAN the content validity was established during development using a formal clinimetric process where patients in a tertiary care centre rated items by importance and frequency to establish relevance [20]. This study provides additional support for the content validity in a community sample of people living with hand arthritis, and by adding new data on the clarity of the items.

Content validity of PRWHE was established during the development of the PRWHE by using semi-structured interviews in patients with distal radius fracture and expert opinion [32]. Later the extension to the PRWHE compared relevance to DASH, based on a comparative trial in a mixed clinical population with hand problems. 
Table 4 Content validity index of item relevancy and clarity, and Modified Kappa agreement of the Thumb Disability Exam (TDX)

\begin{tabular}{|c|c|c|c|c|c|c|c|c|c|}
\hline \multirow[t]{2}{*}{ Item } & \multicolumn{4}{|l|}{ Relevance } & \multicolumn{4}{|l|}{ Clarity } & \multirow[t]{2}{*}{ Interpret } \\
\hline & Agreement & $\begin{array}{l}\mathrm{I}- \\
\mathrm{CVI}\end{array}$ & $\mathrm{Pc}^{* *}$ & $\mathrm{~K}^{* * *}$ & Agreement & $\begin{array}{l}\mathrm{I}- \\
\mathrm{CVI}^{*}\end{array}$ & $\mathrm{Pc}^{* *}$ & $\mathrm{~K}^{* * *}$ & \\
\hline \multicolumn{10}{|c|}{ A. Please indicate your ability to perform these activities with the affected hand } \\
\hline Turn a Key & $54 / 61$ & 0.89 & $\begin{array}{l}< \\
-5\end{array}$ & 0.89 & $51 / 53$ & 0.96 & $\begin{array}{l}<-5 \\
-10\end{array}$ & 0.96 & Excellent \\
\hline Pick up a coin & $52 / 61$ & 0.85 & $\begin{array}{l}<5 \\
-5\end{array}$ & 0.85 & $49 / 51$ & 0.96 & $\begin{array}{l}<10 \\
-5\end{array}$ & 0.96 & Excellent \\
\hline Write & $56 / 61$ & 0.92 & $\begin{array}{l}<10 \\
-5\end{array}$ & 0.92 & $51 / 54$ & 0.94 & $\underset{-5}{<} 10$ & 0.94 & Excellent \\
\hline Squeeze toothpaste & $52 / 60$ & 0.87 & $<_{-5}^{<} 10$ & 0.87 & $51 / 53$ & 0.96 & $\begin{array}{l}<5 \\
-5\end{array}$ & 0.96 & Excellent \\
\hline Hold a glass of water & $50 / 61$ & 0.82 & $\begin{array}{l}<10 \\
-5\end{array}$ & 0.82 & $51 / 54$ & 0.94 & $\begin{array}{l}< \\
-5\end{array}$ & 0.94 & Excellent \\
\hline Turn a doorknob & $52 / 61$ & 0.85 & $\begin{array}{l}<10 \\
-5\end{array}$ & 0.85 & $51 / 53$ & 0.96 & $\begin{array}{l}< \\
-5\end{array}$ & 0.96 & \\
\hline Use a knife to cut food & $54 / 61$ & 0.89 & $<10$ & 0.89 & $51 / 53$ & 0.96 & $<10$ & 0.96 & Excellent \\
\hline
\end{tabular}

\section{B. Please indicate your ability to perform the following task while using both your hands}

\begin{tabular}{|c|c|c|c|c|c|c|c|c|c|}
\hline Open a jar & $57 / 61$ & 0.93 & $\begin{array}{l}<5 \\
-5\end{array}$ & 0.93 & $50 / 51$ & 0.98 & $\begin{array}{l}<5 \\
-5\end{array}$ & 0.98 & Excellent \\
\hline Button a shirt/blouse & $53 / 61$ & 0.87 & $\begin{array}{l}<10 \\
-5\end{array}$ & 0.87 & $49 / 50$ & 0.98 & $\begin{array}{l}<10 \\
-5\end{array}$ & 0.98 & Excellent \\
\hline Tie your shoes & $55 / 61$ & 0.90 & $\begin{array}{l}<5 \\
-5\end{array}$ & 0.90 & $50 / 51$ & 0.98 & $\begin{array}{l}<5 \\
-5\end{array}$ & 0.98 & Excellent \\
\hline Wring a dishcloth/washcloth & $53 / 61$ & 0.87 & $\underset{-5}{<} 10$ & 0.87 & $49 / 51$ & 0.96 & $\underset{-5}{<} 10$ & 0.96 & Excellent \\
\hline
\end{tabular}

II. The following questions refer to the level of pain in your thumb

How often did you have pain in your thumb at rest?

How often did the pain in your thumb interfere with your $\quad 49 / 60$ daily activities?

How often did the pain in your hand interfere with recreational activities?

How often did the pain in your thumb interfere with your $\quad 47 / 60$ sleep?

How often did the pain in your thumb worsen your mood? $\quad 51 / 60$

\begin{tabular}{|c|c|c|c|c|c|c|c|c|}
\hline $50 / 61$ & 0.82 & $\begin{array}{l}<5 \\
-5\end{array}$ & 0.82 & $40 / 52$ & 0.77 & $\begin{array}{l}<-510 \\
-5\end{array}$ & 0.77 & Excellent \\
\hline $49 / 60$ & 0.82 & $\underset{-5}{<} 10$ & 0.82 & $44 / 51$ & 0.86 & $\begin{array}{l}<-5 \\
-5\end{array}$ & 0.86 & Excellent \\
\hline $51 / 60$ & 0.85 & $\begin{array}{l}<5 \\
-5\end{array}$ & 0.85 & $44 / 52$ & 0.85 & $\begin{array}{l}<5 \\
-5\end{array}$ & 0.85 & Excelle \\
\hline $47 / 60$ & 0.78 & $\begin{array}{l}<5 \\
-5\end{array}$ & 0.78 & $44 / 52$ & 0.85 & $\begin{array}{l}<-5 \\
-50\end{array}$ & 0.85 & Excelle \\
\hline $51 / 60$ & 0.85 & $<10$ & 0.85 & $42 / 52$ & 0.81 & $<10$ & 0.81 & Excelle \\
\hline
\end{tabular}

III. The following questions ask about your satisfaction with the indicated hand or thumb over the past week.

\begin{tabular}{|c|c|c|c|c|c|c|c|c|c|}
\hline Motion in your affected thumb & $48 / 58$ & 0.83 & $\underset{-5}{<} 10$ & 0.83 & $47 / 53$ & 0.89 & $\begin{array}{l}<-5 \\
-5\end{array}$ & 0.89 & Excellent \\
\hline Strength of your affected hand & $54 / 57$ & 0.95 & $\begin{array}{l}<5 \\
-50\end{array}$ & 0.95 & $48 / 53$ & 0.91 & $\begin{array}{l}<5 \\
-5\end{array}$ & 0.91 & Excellent \\
\hline Pain level of your affected hand & $52 / 58$ & 0.90 & $\begin{array}{l}<5 \\
-5\end{array}$ & 0.90 & $48 / 53$ & 0.91 & $\begin{array}{l}<5 \\
-5\end{array}$ & 0.91 & Excellent \\
\hline Overall function of your hand & $53 / 58$ & 0.91 & $<_{-5} 10$ & 0.91 & $46 / 52$ & 0.88 & $<_{-5} 10$ & 0.88 & $x c e l l e$ \\
\hline
\end{tabular}

NOTE: *I-CVI: item-level content validity index ${ }^{* *} \mathrm{pc}$ (probability of a chance occurrence) was computed using the formula: $\mathrm{pc}=[\mathrm{N} ! / \mathrm{A} !(\mathrm{N}-\mathrm{A}) !]{ }^{*} .5^{\mathbf{N}}$ where $\mathrm{N}=$ number of raters and $\mathrm{A}=$ number of raters who agree that the item is relevant or clear, ${ }^{* * *} \mathrm{~K}$ (Modified Kappa) was Computed using the formula: $\mathrm{K}=(\mathrm{I}-\mathrm{CVI}-\mathrm{PC}) /(1-$ $\mathrm{PC}$ ). Interpretation criteria for Kappa, using guidelines described in Cicchetti and Sparrow (1981): Fair $=\mathrm{K}$ of 0.40 to 0.59 ; Good = K of 0.60 to 0.74 ; and Excellent $=$ $\mathrm{K}>$ 0.74. I-CVI, item-level content validity index; scale-level content validity index, average (S-CVI/Ave) 
However, neither were quantified, described specific findings in-depth or focused on patients with arthritis. Thus, this study provides novel information on the content validity of the items of the PRWHE, with specific reference to those with hand arthritis. All items of PRWHE were found with very high content validity index in terms of relevance (I-CVI $>0.79$ ) and clarity (ICVI > 0.87).

It might have been expected that the AUSCAN would have more relevance to our sample, than the PRWHE since it a disease-specific PROM. Both point estimate and $\mathrm{CI}$ comparisons indicate that AUSCAN had slightly higher overall scores in terms of relevancy ( $\mathrm{S}-\mathrm{CVI}=0.92$, 95\% CI: 0.90 to 0.94 ) and clarity (S-CVI $=0.99,95 \%$ CI: 0.98 to 1.00$)$ than the PRWHE $(\mathrm{S}-\mathrm{CVI}=0.85,95 \% \mathrm{CI}$ : 0.82 to 0.88 for relevancy and S-CVI $=0.95,95 \%$ CI: 0.93 to 0.97 for clarity). Although the CIs of the respective SCVIs indicate that there was a small statistically significant difference (Table 5) between compared S-CVI values (AUSCAN vs TDX and AUSCAN vs PRWHE), all PROMs met standards of very high content validity. Further, since 6 to 8 additional raters assessed the PRWHE that did not assess the AUSCAN, the small differences may reflect differences in rater pools rather than an actual difference in perceptions.

The TDX is relatively new developed PROM (Noback et al. 2017) [19] that was tested in patients with basal joint arthritis. The TDX demonstrated very high content validity index when assessed in terms of relevancy (S$\mathrm{CVI}=0.87,95 \%$ CI: 0.85 to 0.89$)$ and clarity (S-CVI = 0.91, $95 \%$ CI: 0.89 to 0.94). All the individual items of the TDX had a very high content validity index (I-CVI > 0.77). No previous studies have reported the content validity index of TDX. The item generation of TDX included the review of items from relevant scales (Michigan Hand Questionnaire (MHQ) [33], Disabilities of the Arm, Shoulder, and Hand (DASH) [34], AUSCAN [20], PRWHE [27] and McGill Pain questionnaire [35]). Then, the development process included item reduction and pilot testing and then final item reduction [19]. Thus the items may have benefited from content validity efforts made in developing the scales. Since the thumb is so important for overall hand function, it is not surprising that this thumb questionnaire was found to have validity for patients with hand arthritis.

Our kappa statistics indicated excellent agreement between patient raters after correcting for chance agreement. (K $>0.77)$. The assessment from a large pool of patients $(n>60)$ generated similar scores between the ICVI and $\mathrm{K}$ scores. This has been previously described in the literature when the number of raters increasing and the probability of chance $(\mathrm{Pc})$ decreases the $\mathrm{K}$ agreement and I-CVI values tend to converge [29].

This study provided novel data on the content validity index in 3 different PROMs in patients with hand arthritis. Since few studies address content validity, this is important to support the conceptual foundations of these measures and support their use in clinical practice. While the computation of CVI is relatively easy, its major weakness is the failure to adjust for chance agreement. However, the authors tried to mitigate this problem by calculating a modified kappa agreement [29, 36]. A potential limitation is that the items of the PROMs were not randomized but the items were rated for relevance and clarity in an order (PRWHE, AUSCAN, TDX). Since all three scales were brief, we would think it is unlikely that there was an order effect, especially since the highest scores were found in the questionnaire administered in the middle. CVI is one method of assessing content validity and as a quantitative process are ideally suited to rating existing items, not to identification of potential gaps in important constructs. Ideally CVI should be augmented by qualitative techniques like cognitive interviewing or understanding the dimensions of the underlying construct to be measured. Also, all three questionnaires demonstrated high content validity, and existing evidence confirms that all three provide strong psychometric properties then practical considerations might be the predominant difference that would guide selection. For example, the AUSCAN requires that a license fee must be paid to the developer, whereas the other questionnaires are copyrighted but freely available for all users.

Table 5 Comparison of content validity index (S-CVI) of relevance and clarity

\begin{tabular}{|c|c|c|c|c|c|c|c|}
\hline \multicolumn{4}{|c|}{ Relevance } & \multicolumn{4}{|l|}{ Clarity } \\
\hline & PRWHE & TDX & AUSCAN & & PRWHE & TDX & AUSCAN \\
\hline PRWHE & $\begin{array}{l}0.85 \\
\text { (95\% Cl: } 0.82-0.88)\end{array}$ & $\begin{array}{l}\text { Paired } \\
\text { t-Test }\end{array}$ & $\begin{array}{l}\text { Paired } \\
\text { t-Test }\end{array}$ & PRWHE & $\begin{array}{l}0.95 \\
\text { (95\% Cl: } 0.93-0.97)\end{array}$ & Wilcoxon Signed ranks & Wilcoxon Signed ranks \\
\hline TDX & $p=0.523$ & $\begin{array}{l}0.87 \\
\text { (95\% Cl: } 0.85-0.89)\end{array}$ & $\begin{array}{l}\text { Paired } \\
\text { t-Test }\end{array}$ & TDX & $p=0.153$ & $\begin{array}{l}0.91 \\
\text { (95\% Cl: 0.89-0.94) }\end{array}$ & Wilcoxon Signed ranks \\
\hline AUSCAN & $p<0.001$ & $p=0.001$ & $\begin{array}{l}0.92 \\
(95 \% \text { Cl: } 0.90-0.94)\end{array}$ & AUSCAN & $p=0.001$ & $p=0.002$ & $\begin{array}{l}0.99 \\
(95 \% \text { Cl: } 0.98-1.00)\end{array}$ \\
\hline
\end{tabular}

Paired t-Test: Student's t-Test for Matched Pairs; Wilcoxon Signed Ranks: Wilcoxon Matched-Pairs Signed-Ranks 


\section{Conclusions}

This study demonstrated evidence of very high content validity index for all the individual items and for the overall scale of AUSCAN, PRWHE and TDX for patients with hand arthritis, with high agreement across raters. This augments prior statistical evidence supporting statistical measurement properties, to provide support for the content validity.

\section{Acknowledgements}

Pavlos Bobos was supported by the Canadian Institutes of Health Research (CIHR) Doctoral Award. Joy C MacDermid was supported by a CIHR Chair in Gender, Work and Health and the Dr. James Roth Research Chair in Musculoskeletal Measurement and Knowledge Translation.

\section{Code availability}

Code will be made available upon request.

\section{Authors' contributions}

PB conceived and designed the study, collected, analyzed and interpreted data, wrote the first draft of the article, and contributed to all revisions. JCM and ECB analyzed and interpreted data and contributed to all revisions. EL, RG and LF contributed to study design, collected and interpreted data, and contributed to all revisions. All authors read and approved the final manuscript.

\section{Funding}

This study is supported by the Canadian Institutes of Health Research (CIHR) with funding reference number (FRN: 201710GSD-402,354-282,879) and by an operating grant from the Arthritis Society of Canada.

\section{Competing interests}

The authors declare that they have no conflict of interest.

Data sharing it not permitted by our institutional research ethics board.

\section{Author details}

${ }^{1}$ School of Physical Therapy, Department of Health and Rehabilitation Sciences, Western University, London, ON, Canada. Western's Bone and Joint Institute, Collaborative Program of Musculoskeletal Health Research, Western University, London, ON, Canada. ${ }^{3}$ Roth McFarlane Hand and Upper Limb Centre, St. Joseph's Hospital, London, ON, Canada. ${ }^{4}$ Dalla Lana School of Public Health, Institute of Health Policy, Management and Evaluation, Department of Clinical Epidemiology and Health Care Research, University of Toronto, Toronto, ON, Canada. ${ }^{5}$ McMaster University, Hamilton, ON, Canada. ${ }^{6}$ Department of Hygiene, Epidemiology and Medical Statistics, National and Kapodistrian University of Athens, Athens, Greece. ${ }^{7}$ Department of Mechanical and Materials Engineering, Western University, London, ON, Canada.

Received: 27 May 2020 Accepted: 1 September 2020

\section{Published online: 09 September 2020}

\section{References}

1. Branco JC, Rodrigues AM, Gouveia N, Eusébio M, Ramiro S, Machado PM, et al. Prevalence of rheumatic and musculoskeletal diseases and their impact on health-related quality of life, physical function and mental health in Portugal: results from EpiReumaPt- a national health survey. RMD Open. 2016;2:e000166

2. Dahaghin S, Bierma-Zeinstra SMA, Ginai AZ, Pols HAP, Hazes JMW, Koes BW. Prevalence and pattern of radiographic hand osteoarthritis and association with pain and disability (the Rotterdam study). Ann Rheum Dis. 2005;64:682.

3. Zhang Y, Niu J, Kelly-Hayes M, Chaisson CE, Aliabadi P, Felson DT. Prevalence of symptomatic hand osteoarthritis and its impact on functional status among the ElderlyThe Framingham study. Am J Epidemiol Oxford Academic. 2002;156:1021-7.

4. Bobos P, Nazari G, Szekeres M, Lalone EA, Ferreira L, MacDermid JC. The effectiveness of joint-protection programs on pain, hand function, and grip strength levels in patients with hand arthritis: a systematic review and meta-analysis. J Hand Ther. 2019;32:194-211.
5. Kloppenburg M, Kroon FP, Blanco FJ, Doherty M, Dziedzic KS, Greibrokk E, et al. 2018 update of the EULAR recommendations for the management of hand osteoarthritis. Ann Rheum Dis. 2019;78:16.

6. Cai $P$, Jiang $T$, Li B, Qin X, Lu Z, Le Y, et al. Comparison of rheumatoid arthritis (RA) and osteoarthritis (OA) based on microarray profiles of human joint fibroblast-like synoviocytes: bioinformation for RA and OA interpretation. Cell Biochem Funct. 2019;37:31-41. https://doi.org/10.1002/ cbf.3370 [cited 2020 Apr 28].

7. Fitzpatrick R, Davey C, Buxton M, Jones D. Evaluating patient-based outcome measures for use in clinical trials: a review. Health Technol Assess. 1998:2:1-74 [cited 2020 Apr 17 ] Available from: https:/umw.journalslibrary.nihr.ac.uk/hta/hta2140\#/abstract.

8. Bijlsma JWJ. Patient centred outcomes in osteoarthritis. Ann Rheum Dis 2005:64:1

9. Bobos P, Nazari G, Lu Z, MacDermid JC. Measurement properties of the hand grip strength assessment: a systematic review with meta-analysis. Arch Phys Med Rehabil. 2019;101:553-65.

10. Bobos P, MacDermid JC, Walton DM, Gross A, Santaguida PL. Patientreported outcome measures used for neck disorders: an overview of systematic reviews. J Orthop Sports Phys Ther. 2018;48:775-88.

11. Bobos P, MacDermid J, Nazari G, Furtado R. Psychometric properties of the global rating of change scales in patients with neck disorders: a systematic review with meta-analysis and meta-regression. BMJ Open. 2019;9:e033909.

12. Bobos P, Ziebart C, Furtado R, Lu Z, MacDermid JC. Psychometric properties of the global rating of change scales in patients with low back pain, upper and lower extremity disorders. A systematic review with meta-analysis. J Orthop. 2020;21:40-8.

13. McGee S, Sipos T, Allin T, Chen C, Greco A, Bobos P, et al. Systematic review of the measurement properties of performance-based functional tests in patients with neck disorders. BMJ Open. 2019:9:e031242.

14. Terwee CB, Prinsen CAC, Chiarotto A, Westerman MJ, Patrick DL, Alonso J, et al. COSMIN methodology for evaluating the content validity of patientreported outcome measures: a Delphi study. Qual Life Res. 2018;27:1159-70.

15. Mokkink LB, Terwee CB, Patrick DL, Alonso J, Stratford PW, Knol DL, et al. The COSMIN study reached international consensus on taxonomy, terminology, and definitions of measurement properties for health-related patient-reported outcomes. J Clin Epidemiol Elsevier. 2010;63:737-45.

16. Patrick DL, Burke LB, Gwaltney CJ, Leidy NK, Martin ML, Molsen E, et al. Content validity-establishing and reporting the evidence in newly developed patientreported outcomes (PRO) instruments for medical product evaluation: ISPOR PRO good research practices task force report: part 2-assessing respondent understanding. Value Health Elsevier. 2011;14:978-88.

17. Streiner DL, Norman GR, Cairney J. Health measurement scales: a practical guide to their development and use. Health measurement scales. Oxford: Oxford University Press; 2015. [cited 2020 Apr 17]. https://doi.org/10.1093/ med/9780199685219.001.0001/med-9780199685219.

18. McQuillan TJ, Vora MM, Kenney DE, Crisco JJ, Weiss A-PC, Ebert KA, et al. The AUSCAN and PRWHE demonstrate comparable internal consistency and validity in patients with early thumb carpometacarpal osteoarthritis: HAND [Internet]. Los Angeles: SAGE PublicationsSage CA; 2017 [cited 2020 Apr 17]. https://doi.org/10.1177/1558944717729217.

19. Noback PC, Lombardi JM, Seetharaman M, Lee DH, Strauch RJ, Rosenwasser MP. Development and validation of a disease-specific questionnaire for basal joint arthritis. J Wrist Surg. 2017;06:126-33 Thieme Medical Publishers.

20. Bellamy N, Campbell J, Haraoui B, Buchbinder R, Hobby K, Roth JH, et al. Dimensionality and clinical importance of pain and disability in hand osteoarthritis: development of the Australian/Canadian (AUSCAN) osteoarthritis hand index. Osteoarthr Cartil. 2002;10:855-62.

21. Mehta SP, MacDermid JC, Richardson J, Maclntyre NJ, Grewal R. A systematic review of the measurement properties of the patient-rated wrist evaluation. J Orthop Sports Phys Ther. 2015 JOSPT, Inc. JOSPT, 1033 North Fairfax Street, Suite 304, Alexandria, VA 22134-1540 [cited 2020 Apr 17]. https://doi.org/10.2519/jospt.2015.5236.

22. Allen KD, Jordan JM, Renner JB, Kraus VB. Validity, factor structure, and clinical relevance of the AUSCAN osteoarthritis hand index. Arthritis Rheum. John Wiley \& Sons, Ltd. 2006;54:551-6.

23. Allen K, DeVellis R, Renner J, Kraus V, Jordan J. Validity and factor structure of the AUSCAN Osteoarthritis Hand Index in a community-based sample. Osteoarthr Cartil. 2007;15:830-6 [cited 2020 Aug 15] Available from: https:// pubmed.ncbi.n/m.nih.gov/17331744/.

24. Haugen IK, Moe RH, Slatkowsky-Christensen B, Kvien TK, van der Heijde D, Garratt A. The AUSCAN subscales, AIMS-2 hand/finger subscale, and FIOHA were not unidimensional scales. J Clin Epidemiol. 2011;64:1039-46. 
25. Qualtrics XM // The leading experience management software. Qualtrics. [cited 2020 Apr 17]. Available from: https://www.qualtrics.com/.

26. MacDermid JC, Tottenham V. Responsiveness of the disability of the arm, shoulder, and hand (DASH) and patient-rated wrist/hand evaluation (PRWHE) in evaluating change after hand therapy. J Hand Ther. Elsevier. 2004;17:18-23.

27. Packham T, MacDermid JC. Measurement properties of the patient-rated wrist and hand evaluation: Rasch analysis of responses from a traumatic hand injury population. J Hand Ther Elsevier. 2013;26:216-24.

28. MacDermid JC, Wessel J, Humphrey R, Ross D, Roth JH. Validity of self-report measures of pain and disability for persons who have undergone arthroplasty for osteoarthritis of the carpometacarpal joint of the hand. Osteoarthr Cartil Elsevier. 2007;15:524-30.

29. Polit DF, Beck CT, Owen SV. Is the CVI an acceptable indicator of content validity? Appraisal and recommendations. Res Nurs Health. John Wiley \& Sons, Ltd. 2007:30:459-67.

30. Cicchetti DV, Sparrow SA. Developing criteria for establishing interrate reliability of specific items: applications to assessment of adaptive behavior. Am J Ment Defic US: American Assn on Mental Retardation. 1981;86:127-37.

31. MacFarland TW, Yates JM. Wilcoxon matched-pairs signed-ranks test. In: MacFarland TW, Yates JM, editors. Introduction to nonparametric statistics for the biological sciences using R [internet]. Cham: Springer International Publishing; 2016 [cited 2020 May 5]. p. 133-75. https://doi.org/10.1007/9783-319-30634-6_5.

32. Kleinlugtenbelt $\mathrm{W}$, Krol RG, Bhandari M, Goslings JC, Poolman RW, Scholtes VAB. Are the patient-rated wrist evaluation (PRWE) and the disabilities of the arm, shoulder and hand (DASH) questionnaire used in distal radial fractures truly valid and reliable? Bone Joint Res. 2018 The British Editorial Society of Bone and Joint Surgery London [cited 2020 Apr 25]. https://doi.org/10.1302/ 2046-3758.71.BJR-2017-0081.R1.

33. Shauver MJ, Chung KC. The Michigan hand outcomes questionnaire (MHQ) after 15 years of field trial. Plast Reconstr Surg. NHH Public Access. 2013;131:779e.

34. Gummesson C, Atroshi I, Ekdahl C. The disabilities of the arm, shoulder and hand (DASH) outcome questionnaire: longitudinal construct validity and measuring self-rated health change after surgery [Internet]. BMC Musculoskelet Disord. 2003; [cited 2020 Aug 9]. Available from: https:// pubmed.ncbi.nlm.nih.gov/12809562/.

35. Melzack R. The McGill Pain Questionnaire: major properties and scoring methods [Internet]. Pain. 1975;1:277-99 [cited 2020 Aug 9]. Available from: https://pubmed.ncbi.nlm.nih.gov/1235985/.

36. Polit DF, Beck CT. The content validity index: are you sure you know what's being reported? Critique and recommendations. Res Nurs Health. John Wiley \& Sons, Ltd. 2006;29:489-97.

\section{Publisher's Note}

Springer Nature remains neutral with regard to jurisdictional claims in published maps and institutional affiliations.

Ready to submit your research? Choose BMC and benefit from:

- fast, convenient online submission

- thorough peer review by experienced researchers in your field

- rapid publication on acceptance

- support for research data, including large and complex data types

- gold Open Access which fosters wider collaboration and increased citations

- maximum visibility for your research: over $100 \mathrm{M}$ website views per year

At $\mathrm{BMC}$, research is always in progress.

Learn more biomedcentral.com/submissions 